\title{
Reflexões sobre a pesquisa no cotidiano profissional do assistente social
}

\author{
Reflections on professional research in everyday social worker
}

\author{
Lucia Maria Patriota \\ Dayse Cristina Nunes do Nascimento ** \\ Adriana Freire Pereira Férriz ${ }^{* * *}$ \\ Sandra Amélia Sampaio Silveira ${ }^{* * * *}$
}

\begin{abstract}
Resumo:
Este artigo tem como foco a prática da pesquisa no cotidiano profissional do assistente social. Os objetivos da investigação foram: analisar o papel da pesquisa na prática cotidiana dos supervisores de estágio curricular do Curso de Serviço Social da Universidade Estadual da Paraíba; conhecer como a mesma é entendida pelos respectivos profissionais; verificar se e como se dá sua utilização no cotidiano de trabalho; e identificar as dificuldades colocadas por esses profissionais para sua utilização no cotidiano profissional. Compreendeu um estudo exploratório e descritivo com abordagem quanti-qualitativa. Os sujeitos da pesquisa foram 20 assistentes sociais supervisores de estágio supervisionado do Curso de Serviço Social da Universidade Estadual da Paraíba. Para a coleta de dados foi utilizado um questionário e os dados obtidos foram submetidos à análise de conteúdo. De acordo com os resultados obtidos, a pesquisa é entendida pela maioria dos sujeitos como um meio de apreensão/compreensão da realidade, como um componente fundamental ao exercício profissional. Os sujeitos pesquisados foram unânimes em afirmar a existência da relação serviço social x pesquisa. Quanto às dificuldades apontadas para a prática da pesquisa, destacam-se o fator tempo, as condições objetivas desfavoráveis e as limitações postas pela própria formação. Apesar de todos os avanços, a pesquisa, no universo em estudo, ainda é escassa, desarticulada e pouco expressiva.
\end{abstract}

Palavras-Chave: Pesquisa; Supervisores; Estágio. Social; Profissional.

\section{Abstract:}

This article focuses on the practice of research in everyday professional social worker. The research objectives were to analyze the role of research in everyday practice of supervisors curricular Course of Social Work at the State University of Paraiba, to know how research is perceived by the respective professionals; see if and how research is used in the everyday work, and to identify the difficulties posed by these professionals for research use in daily work. Realized an exploratory and descriptive quantitative

\footnotetext{
* Mestre em Saúde Coletiva. Docente do Curso de Serviço Social da Universidade Estadual da Paraíba. E-mail: luciapatriota@yahoo.com.br

** Assistente Social. Coordenadora do CREAS de Boqueirão/PB. E-mail: Dayse crys15@hotmail.com

*** Doutora em Sociologia. Docente do Curso de serviço social da Universidade Estadual da Paraíba. E-mail: Adrian jua@yahoo.com.br

**** Mestre em Serviço Social. Docente do Curso de Serviço Social da Universidade Estadual da Paraíba. Email: samelias2@yahoo.com.br
} 
and qualitative approach. The study subjects were 20 social workers supervisors supervised the course of Social Work at the State University of Paraiba. For data collection questionnaire was used and data were subjected to content analysis. According to the survey results is understood by most subjects as a means of apprehension / comprehension of reality, as a key component to professional practice. Study subjects were unanimous in affirming the existence of the relationship $x$ social service research. Regarding difficulties for research practice stand out from the time factor, the unfavorable objective conditions and limitations posed by the training itself. Even considering all the advances, research in the group studied is still scarce, inarticulate and inexpressive.

Keywords: Search. Supervisors. Training. Social. Professional.

\section{Introdução}

O presente artigo é um recorte de uma pesquisa intitulada "A pesquisa na prática cotidiana dos supervisores de estágio curricular do curso de Serviço Social da Universidade Estadual da Paraíba" (NASCIMENTO, 2012), que foi desenvolvida junto ao Programa Institucional de Bolsas de Iniciação Científica (PIBIC), na cota 2011/2012, como parte do projeto integrado Pesquisa e Serviço Social.

A pesquisa dá continuidade e complementaridade aos estudos que temos empreendido na condução do componente curricular Pesquisa em Serviço Social II e na supervisão acadêmica de estágio supervisionado do Departamento de Serviço Social da Universidade Estadual da Paraíba.

O interesse pela temática decorre da prática docente que nos tem posto em contado direto com os supervisores de estágio supervisionado, que acompanham discentes nas diferentes instituições. Essa aproximação tem nos conduzido a profícuas reflexões em torno desse complexo campo do conhecimento e prática e sua intercessão com o serviço social.

Esperamos, com o presente estudo, fomentar discussões não só no âmbito acadêmico, mas nos espaços sócio-ocupacionais, de modo que a pesquisa possa não só ser compreendida na sua importância, mas utilizada pela categoria no dia a dia do trabalho, conforme previsto no Código de Ética dos Assistentes Sociais (1993). Afinal, a atitude investigativa é o que favorece ao assistente social o rompimento com o pragmatismo, pois proporciona inquietação e reflexão constantes, determinando, assim, uma prática profissional coerente e consistente. 
O objetivo geral do estudo foi analisar o papel da pesquisa na prática cotidiana dos supervisores de estágio curricular do Curso de Serviço Social da UEPB; e por objetivos específicos foram: conhecer como a pesquisa é entendida pelos supervisores de estágio curricular do Curso de Serviço Social da UEPB; verificar se e como a pesquisa é utilizada no cotidiano de trabalho dos referidos profissionais; e identificar as dificuldades colocadas por esses profissionais para a utilização da pesquisa no cotidiano profissional.

\section{O Serviço Social: algumas considerações}

O Serviço Social surgiu, no Brasil, na década de 1930, ligado à Igreja Católica, que tinha como principal objetivo a recristianização da sociedade por meio do vasto movimento conhecido como Reação Católica. Por meio deste movimento, ações de caridade e benevolência eram desenvolvidas por mulheres da alta sociedade, que ficaram conhecidas como "Damas de Caridade". Data deste período o agravamento da "questão social", que, de acordo com lamamoto e Carvalho $(1985$, p. 77$)$ :

[...] não é senão as expressões do processo de formação e desenvolvimento da classe operária e de seu ingresso no cenário político da sociedade, exigindo seu reconhecimento como classe por parte do empresariado e do Estado. É a manifestação, no cotidiano da vida social, da contradição entre o proletariado e a burguesia, a qual passa a exigir outros tipos de intervenção, mais além da caridade e repressão. (IAMAMOTO E CARVALHO, 1985, p. 77)

Com o início do processo de industrialização, que se deu nesse período, em substituição ao modelo econômico agroexportador, e o consequente crescimento da população nas áreas urbanas, houve a necessidade de intervenção, por parte do Estado, para conter o movimento da classe proletária que reivindicava melhores condições de vida, moradia, trabalho e saúde. O Estado passa, então, a criar mecanismos de controle por meio de políticas sociais para dar respostas às manifestações da "questão social" e busca, com isso, preparar uma mão de obra especializada que possa contribuir para a manutenção da ordem vigente. É em meio a esse processo que surgem as primeiras escolas de Serviço Social, em 1936, em São Paulo, e, em 1937, no Rio de Janeiro.

Na década de 1940, o Serviço Social passa por um processo de institucionalização e legitimação da profissão, a partir do surgimento e desenvolvimento das grandes instituições assistenciais e previdenciárias, criadas pelo Estado, fato que implicará 
diretamente na expansão do mercado de trabalho do assistente social. Nesse momento, no Brasil, a profissão recebe influência norte-americana e passa a utilizar, em sua prática, as abordagens de caso, grupo e desenvolvimento de comunidade. É um período no qual:

[...] o Serviço Social deixa de ser um instrumento de distribuição da caridade privada das classes dominantes, para se transformar, prioritariamente, em uma das engrenagens de execução da política social do Estado e de setores empresariais (IAMAMOTO, 2008, p. 31).

Nos anos de 1950, o Serviço Social encontrava-se consolidado e reconhecido na divisão sociotécnica do trabalho, integrando a população às regras governamentais desenvolvimentistas (RODRIGUES; FÉRRIZ; NASCIMENTO, 2011).

Nas décadas de 1960 e 1970, ocorre o Movimento de Reconceituação do Serviço Social no Brasil e na América Latina, cujo intuito era de romper com o conservadorismo na profissão. Segundo Netto (2007), no Brasil, o movimento baseou-se em três direções/ perspectivas que constituíram o processo de renovação: a perspectiva modernizadora; a perspectiva de reatualização do conservadorismo; e a perspectiva de intenção de ruptura com o Serviço Social tradicional.

Em consonância com o processo de renovação, o Serviço Social brasileiro busca se aproximar do marxismo na tentativa de renunciar ao conservadorismo que caracterizava a profissão. No entanto, essa aproximação não se deu de forma direta, o que se constituiu em um "marxismo sem Marx". Nesse sentido, Netto (2005, p.10) registra que:

\footnotetext{
Em meados dos 1970, a renovação profissional materializada na Reconceituação viu-se congelada: seu processo não decorreu por mais de uma década. E seu ocaso não se deveu a qualquer esgotamento ou exaurimento imanente; antes, foi produto da brutal repressão que então se abateu sobre o pensamento crítico latino- americano [...]. (NETTO, 2005, p. 10)
}

Nesse período, também se registra a inserção dos cursos de Serviço Social, no âmbito acadêmico, o que impulsionou um forte debate sobre a formação profissional. Destacamos a realização, em 1979, do III Congresso Brasileiro de Assistentes Sociais, conhecido como o "Congresso da Virada", movimento de oposição à direção conservadora da profissão (SILVA, 1995).

Nos anos 1980, ocorre a consolidação da pesquisa no âmbito do Serviço Social e o seu reconhecimento por parte das principais agências de fomento à pesquisa no país, o 
Conselho Nacional de Desenvolvimento Científico e Tecnológico (CNPq) e a Coordenação de Aperfeiçoamento de Pessoal de Nível Superior (CAPES), como produtora de conhecimento. Conforme registros de Netto (1996, p. 112):

[...] a década de oitenta assinalou a maioridade do Serviço Social no Brasil no domínio da elaboração teórica. Nesse decênio, desenvolveu-se, no interior da categoria, uma "divisão de trabalho" (uma especialização) que é própria das profissões amadurecidas: a criação de um segmento diretamente vinculado à pesquisa e à produção de conhecimentos. (NETTO, 1996, p. 112)

É um momento de maturidade da profissão, que busca estabelecer novas bases de compreensão do seu passado histórico para se posicionar em relação às complexas demandas sociais, no âmbito da divisão sociotécnica do trabalho (BOURGUIGNON, 2007).

Nos anos de 1990, o Serviço Social é marcado pela ampliação do seu campo de atuação profissional, o que traz à tona a discussão e a materialização do projeto éticopolítico, por meio da Lei № 8.662/93, que regulamenta a profissão, do Código de Ética Profissional de 1993 e das Diretrizes Curriculares de 1996, resultantes do posicionamento crítico da categoria diante das novas configurações apresentadas pelo neoliberalismo e pelo capital. Segundo lamamoto (2003, p. 51):

\footnotetext{
Os assistentes sociais ingressam nos anos de 1990, como uma categoria que também é pesquisadora, reconhecida, como tal, pelas agências de fomento. Por outro lado, amadurecem suas formas de representação político-corporativas, contando com órgãos de representação acadêmica e profissional, reconhecidos e legitimados. (IAMAMOTO, 2003, p. 51)
}

As Diretrizes Curriculares de 1996 evidenciam um significativo avanço na formação profissional dos assistentes sociais, pois passam a adotar uma perspectiva de "visão crítica comprometida com a transformação social". Buscou-se estruturar a formação em articulação com a teoria, a história, a metodologia e a pesquisa, para formar estudantes com base nas análises críticas à sociedade capitalista (FALEIROS, 2005).

Mesmo com os significativos avanços da profissão, o Serviço Social, na década de 1990 e na entrada século XXI, passa por um processo contraditório, pois tem que enfrentar o desafio de compreender a lógica do capitalismo contemporâneo, que trouxe mudanças no mundo do trabalho e acabou por afetar os sistemas de proteção social e a política social. Assim, o profissional é "desafiado a compreender e intervir" nas novas configurações e manifestações da "questão social" (CARVALHO; SILVA, 2005). 
A conjuntura atual coloca novos desafios para o Serviço Social, no âmbito da concretização do seu projeto profissional. Esses desafios são resultantes do avanço do Neoliberalismo e do capital sobre as relações sociais, o que traz à tona o processo de precarização das relações de trabalho (terceirização, contratos parciais e temporários etc.) e a expansão da divisão do trabalho e da propriedade privada. Em meio a essas novas configurações no mundo do trabalho, o assistente social é desafiado a fazer do projeto ético-político um guia na condução de suas ações cotidianas.

De acordo com lamamoto (2008), podemos verificar, na atualidade, uma tensa relação entre o projeto profissional e a condição de trabalhador assalariado do assistente social, que, desde a década de 1980 , tem sua profissão reconhecida como especialização do trabalho e passa a ser considerado um trabalhador inserido na divisão social e técnica do trabalho.

\section{O Serviço Social e a Pesquisa}

A prática da pesquisa, com a conotação crítica e com a ênfase que hoje é dada à mesma, não se fez presente nos primórdios da profissão, o que se deve, em grande medida, ao referencial teórico-metodológico de base conservadora que orientou o Serviço Social tradicional.

A formação profissional instituída com o surgimento das primeiras escolas, na década de 1930, pautou-se na Doutrina Social da Igreja e no neotomismo, o que implicava em uma compreensão da questão social como problema moral e religioso, na leitura acrítica e a-histórica da sociedade e em uma prática profissional voltada à integração dos indivíduos (clientes) às relações sociais vigentes, pela via da mudança de seus valores e comportamentos (YAZBEK; SILVA, 2005).

Na verdade, a formação profissional, historicamente, não deu a ênfase hoje dada à pesquisa. De acordo com Sposati (2007, p. 17):

É após o processo de reconceituação e, com ele, da construção da identidade social latino-americano do Serviço Social que, ao questionar sua 'base científica' europeu-americana, a preocupação com o conhecimento no e para o Serviço Social se fortalece. (SPOSAT, 2007, p.17) 
A relação do Serviço Social com a pesquisa surge em função de um processo de mudanças na sociedade, nos aspectos sociais, econômicos, políticos e culturais, que resultam em um conjunto de problemáticas que exigem novas respostas profissionais. Dessa forma, coube ao Assistente Social a busca de tais respostas, através da pesquisa, com a finalidade de compreender a realidade social e propor ações visando a minimizar as manifestações da "questão social".

Portanto, houve um amadurecimento intelectual da categoria, proveniente da ampliação das demandas sociais, o que acabou por revelar uma profissão capaz de gestar conhecimentos que lhe proporcionam subsídios teórico-metodológicos coerentes com seus princípios, propósitos e cotidiano profissional, embora, inicialmente, com verificação mais ampla no ambiente acadêmico.

Foi somente na década de 1960 que se iniciou um processo de renovação do Serviço Social brasileiro, o que provocou um desgaste do tradicionalismo até então predominante na profissão. Esse fenômeno se edificou em consonância com o Movimento de Reconceituação (MR), parte integrante do processo latino americano e internacional de erosão do Serviço Social tradicional.

No lastro desse processo, no qual se delinearam linhas diferenciadas de fundamentação teórico-metodológicas e de referenciais interventivos para a profissão, foram constituídas, nos anos de 1970 e 1980, as pós-graduações, com o surgimento dos programas de mestrado e doutorado na área de Serviço Social no Brasil.

É possível verificar que a pesquisa, aos poucos, deixa de ser considerada como uma mera matéria básica e passa a ser concebida como um dos princípios e uma condição da formação profissional. A pesquisa insere-se, assim, como uma exigência para a superação do pragmatismo, que foi e, ainda, é marcante no serviço social.

A atitude investigativa permite ao assistente social olhar para além do que está posto, transcendendo a realidade tal como se apresenta. Assim, é possível desvendar as relações e construir conhecimentos acerca das mesmas, favorecendo, a partir de reflexões e críticas, uma prática profissional consistente e coerente.

Nas instituições em que o assistente social atua, o mesmo tem acesso a muitos dados, que, se analisados, poderiam ajudar na sua prática cotidiana e ser usados para produzir conhecimentos, mas muitos profissionais não os utilizam com esse intuito. Nesse 
sentido, Setubal (2007, p. 66) assinala o quanto é "necessário o desenvolvimento da prática investigativa, não apenas para cumprir exigências institucionais de ordem acadêmica, mas também para cumprir exigências do Serviço Social como profissão historicamente situada."

Nesse sentido, estimular a pesquisa no cotidiano do trabalho profissional é algo, sem dúvida, necessário e fundamental, pois, não obstante os avanços alcançados na produção do conhecimento no Serviço Social no meio acadêmico, nem todos os(as) assistentes sociais utilizam esse instrumento no cotidiano do trabalho nas instituições (BOURGUIGNON, 2007).

Orientado pelo compromisso ético-político, o conhecimento construído pelos profissionais precisa ganhar força social e romper com os muros da academia e do próprio Serviço Social, para ser capaz de, por meio de uma prática crítica e propositiva, interferir nas condições de vida do cidadão (BOURGUIGNON, 2007). Esse conhecimento produzido deve retornar à sociedade e contribuir para a transformação da mesma.

A pesquisa, na prática do assistente social, pode auxiliá-lo a desenvolver uma atuação mais consistente, pois o instrumentaliza a refletir criticamente sobre o processo histórico em que está inserido. Segundo Setubal (2007, p. 68), “ao trazer para o centro a preocupação com a pesquisa, o Serviço Social reconhece a sua complexidade como profissão histórica, inserida e construída no movimento real da formação social capitalista".

A produção de conhecimento traz para os profissionais um aparato teóricometodológico que dá sustentação à prática profissional, pois se baseia nas experiências sociais adquiridas durante sua atuação junto aos usuários, que buscam os seus serviços nas instituições em que atuam.

\begin{abstract}
A intervenção, através de suas intenções, seus projetos e ações cotidianas, estabelece as mediações entre os conhecimentos e as demandas sociais. Desta forma, estas mediações são apreendidas no real e reconstruídas teoricamente, na medida em que o profissional passa da intenção, apoiando-se em pesquisa sistemática e crítica dos fenômenos sociais que define estratégias, meios e recursos necessários para o alcance de seus fins (BOURGUIGNON, 2007, p. 53).
\end{abstract}

A partir de todas as considerações aqui tecidas, podemos constatar que é inaceitável que o assistente social seja considerado apenas um mero executor de programas sociais, 
de caráter focalista, paliativo e excludente, usados, na maioria das vezes, para dar respostas imediatas às necessidades das populações.

\section{Metodologia da Pesquisa}

A pesquisa compreendeu um estudo exploratório e descritivo, com abordagem quanti-qualitativa. O método de abordagem da realidade foi o crítico-dialético, que permite apreender o fenômeno estudado numa relação permanente entre o particular e o geral, considerando os aspectos históricos, econômicos, sociais, políticos, ideológicos e culturais que permeiam o objeto de estudo.

O estudo é fruto de um projeto de pesquisa integrado, composto por dois subprojetos que trazem como objeto de estudo comum a produção do conhecimento no âmbito do Serviço Social. O enfoque é a prática da pesquisa em diferentes espaços sócioocupacionais: campos de estágio supervisionado do Curso de Serviço Social da Universidade Estadual da Paraíba (UEPB) e na graduação, a partir dos TCC resultantes do estágio curricular (PIBIC/UEPB - cota 2011/2012), o que dá continuidade e complementaridade aos estudos que temos empreendido em torno da trajetória histórica do Curso de Serviço Social da referida universidade.

A coleta de dados da pesquisa ocorreu no mês de novembro de 2011 e, dos 29 assistentes sociais supervisores de Estágio Curricular do Curso de Serviço Social da UEPB, no período 2011/2012, 20 responderam o instrumento de coleta de dados, totalizando uma amostra de 68,9\% do universo. Para a coleta de dados, foi utilizado um questionário com perguntas abertas e fechadas e, para tratamento dos dados, foi realizada uma análise de conteúdo.

O projeto foi encaminhado para apreciação do Comitê de Ética em Pesquisa (CEP) desta Universidade e atentou ao que preconiza a Resolução 196/96 do Conselho Nacional de Saúde (CNS). Assumiu o compromisso de respeito à autonomia dos sujeitos da pesquisa, garantindo-Ihes todas as medidas de proteção: sigilo, anonimato e, ainda, o esclarecimento acerca dos objetivos da pesquisa e do que será feito com seus resultados, por meio do Termo de Consentimento Livre e Esclarecido (TCLE), que foi elaborado em duas vias, sendo uma retida pelo sujeito da pesquisa e uma arquivada pelo pesquisador responsável pela mesma. 
Para o tratamento e análise dos dados, foi empregada a técnica de análise de conteúdo, que permite compreender criticamente os sentidos e as significações explícitas e implícitas da fala dos sujeitos. Seguimos as fases da análise de conteúdo que, de acordo com Bardin (1979 apud RICHARDSON, 2007), se organizam em: 1) a pré-análise, que constitui o momento propriamente dito da organização, cujo objetivo é operacionalizar e estruturar as ideias; 2 ) a análise do material, que consiste na codificação e categorização dos dados; 3) o tratamento dos resultados, a inferência e a interpretação.

\section{Resultados Obtidos}

Reiteramos que os resultados, aqui apresentados, compõem parte do Relatório de Iniciação Científica, PIBIC cota 2011/2012 (NASCIMENTO, 2012). A coleta de dados da pesquisa ocorreu no mês de novembro de 2011, momento em que acontecia uma das atividades do Curso de Capacitação Continuada para os Supervisores de Estágio Curricular, desenvolvido no Departamento de Serviço Social da Universidade Estadual da Paraíba.

Dos 29 assistentes sociais supervisores de Estágio Curricular do Curso de Serviço Social da UEPB, no período $2011 / 2012$, vinte responderam o instrumento de coleta de dados, totalizando uma amostra de $68,9 \%$ do universo.

Os dados da pesquisa evidenciam uma tendência histórica no Serviço Social: o predomínio do sexo feminino. Neste estudo, $100 \%$ da amostra é composta por mulheres. Tal evidência também se revelou em pesquisa realizada pelo Conselho Federal de Serviço Social (2005) sobre o perfil dos assistentes sociais no Brasil, que revelou um total de $97 \%$ assistentes sociais do sexo feminino, no país, e apenas $3 \%$ do sexo masculino.

No curso de Serviço Social da UEPB, no ano de 2011, dos 524 alunos matriculados, 50 são homens e 474, mulheres, o que confirma a média nacional de maioria do sexo feminino no curso (RODRIGUES; FÉRRIZ; NASCIMENTO, 2011).

Quanto à faixa etária das entrevistadas, observou-se que, do total de 20 entrevistadas, 10,0\% têm entre 20 a 29 anos de idade; 20,0\%, de 30 a 39 anos; 35,0\%, de 40 a 49 anos; $30,0 \%$, de 50 a 59 anos; e 5,0\%, mais de 60 anos.

Quanto ao tempo de formação profissional dos sujeitos, 15,0\% têm menos de 5 anos; 25,0\%, entre 5 e 10 anos; 35,0\%, entre 11 e 19 anos; e 25,0\%, mais de 20 anos de formação. 
Queremos chamar a atenção para o fato de que se $25 \%$ dos sujeitos pesquisados concluíram o curso de graduação há mais de 20 anos. É pouco provável que esses profissionais, hoje supervisores de estágio, tenham tido, no momento de sua formação, um contato direto com a pesquisa, pois as Diretrizes Curriculares de 1996 ainda não haviam sido implantadas.

Destacamos, ainda, o fato de que, de acordo com levantamento realizado junto ao acervo da biblioteca setorial do referido curso, dos 1.597 TCCs produzidos ao longo de seus 54 anos de existência, apenas 333 foram elaborados com base em pesquisa. Somente nos anos 2.000, houve uma inversão nessa situação, pois foram produzidos 308 TCCs resultantes de pesquisa, ou seja, nos últimos 13 anos do curso, a pesquisa tem deixado de ser considerada como mera matéria básica e tem passado a ser concebida como um dos princípios e uma condição para a formação profissional.

A área de atuação das profissionais entrevistadas é bastante variada: $45,0 \%$ atua na área da Assistência no Centro de Referência da Assistência Social (CRAS); 25,0\%, na área da Saúde; 15,0\%, na área da Infância e Juventude; 5,0\%, na área da Educação; 5,0\%, na área da Segurança Pública; e 5,0\%, em Organização Não-Governamental (ONG).

Conforme visto, os profissionais envolvidos na pesquisa estão inseridos em serviços/áreas de significativa vulnerabilidade social, onde as múltiplas expressões da questão social estão presentes. Nesses contextos, estão inseridos também os estagiários de Serviço Social, os quais encontram, nesses espaços, a oportunidade do exercício da investigação da realidade e da síntese da relação teoria-prática, por meio da interlocução entre a universidade e o mundo do trabalho.

Quanto à concepção de pesquisa identificada nas falas dos sujeitos pesquisados, verificamos que a mesma é entendida por alguns como um meio para análise/compreensão/apreensão do real, como se verifica nos depoimentos abaixo:

A pesquisa configura-se como instrumento de análise/investigação de situações que compõem a realidade, a fim de compreendê-las [...] (Entrevistada 02)

Uma forma de apropriação da realidade na qual se pretende intervir. (Entrevistada 05)

Um estudo que se faz quando queremos conhecer uma realidade ou quando queremos avaliar as mudanças ocorridas numa determinada realidade [...] (Entrevistada 07) 
Pesquisa é a maneira de conhecer uma realidade social. (Entrevistada 08)

É uma maneira de obter conhecimentos a respeito de algo. (Entrevistada 12)

Uma forma de entender a realidade de um certo público [...] (Entrevistada 20)

Conforme Bourguignon (2008), indagar-se, questionar-se, perguntar-se pelo desconhecido faz parte da natureza humana e, como condição ontológica, está presente nas intenções e ações do homem. Entretanto, a autora chama a atenção para o fato de que esse processo - digamos, natural - deve ser embasado em uma direção teórico-crítica, para que se possa, de fato, compreender a realidade em suas múltiplas manifestações. Suas reflexões reiteram, constantemente, o fato de que pesquisa não se faz sem esforço e orientação teórico-metodológica.

A autora ressalta, ainda, que o profissional de Serviço Social precisa conhecer a realidade em sua complexidade e, por meio de um diálogo permanente com a mesma, aprender e construir categorias explicativas que orientem seu fazer profissional, o que não foi possível identificar nas falas dos sujeitos abordados. Pesquisar é mais que levantar elementos da realidade, é descobrir e/ou redescobrir verdades; é olhar, sistematicamente, a realidade, é mais que sistematizar, é problematizar.

Alguns sujeitos deixam evidente que há uma apreensão de elementos postos pela realidade nas quais estão inseridos, mas tais elementos não são problematizados, apenas utilizados de forma a orientar a prática imediata.

Estamos sempre sistematizando/ revendo e avaliando nossas ações cotidianas através da construção de documentos elaborados a partir do trabalho realizado (relatórios quanti-qualitativos). (Entrevistada 02)

Antes de propor qualquer prática ou atividade na organização, realizamos pesquisa ou consulta de demanda, de forma a não impor a prática ao usuário. (Entrevistada 05)

Atualizando dados, estatísticas, informações sobre a área de atuação. (Entrevistada 12)

[...] no espaço institucional em que atuo se faz necessário pesquisar diversos elementos da realidade dos usuários para poder intervir. (Entrevistada 13)

Conforme visto, não há, nas falas apresentadas, elementos que evidenciem a compreensão da pesquisa enquanto produção de conhecimento, enquanto análise crítica 
das questões presentes no cotidiano profissional, tanto em suas dimensões macroscópicas quanto em suas manifestações cotidianas. Essa postura, entretanto, é fundamental ao assistente social, pois este deve ser criativo e inventivo, capaz de entender o tempo presente e nele atuar, contribuindo para moldar os rumos de sua história, conforme lamamoto (2003).

Bourguignon (2008) ressalta que a sistematização do conhecimento é um primeiro e importante nível de aproximação da realidade, necessário para que o profissional organize os conhecimentos específicos de sua área de atuação e identifique demandas da população com a qual trabalha. Entretanto, destaca a importância de se buscar um nível mais elevado: o da construção de conhecimento em torno de um objeto específico, por meio da problematização do mesmo. Nesse sentido, conforme Netto (1989):

[...] a sistematização de dados (ou aspectos, traços, facetas) pertinentes a um fenômeno, grupo ou processo constitui um procedimento prévio e necessário à reflexão teórica. Vale dizer, os procedimentos sistematizadores, especialmente fundados na atividade analítica da intelecção configuram um passo preliminar e compulsório da elaboração teórica - sem, no entanto, confundir-se com ela (apud BOURGUIGNON, 2008, p. 131).

Também foi possível identificar, entre os sujeitos, uma forte associação da pesquisa com a atuação/prática profissional:

[...] processo então essencial para atuação profissional. O assistente social precisa conhecer para atuar na sua área. (Entrevistada 04)

Às vezes, torna-se inviável dar continuidade a um atendimento el ou acompanhamento social sem nos apoderarmos de informações precisas. (Entrevistada 06)

É necessário que se coloque a pesquisa no nosso cotidiano, como forma de aperfeiçoar nossos conhecimentos e melhorar a qualidade dos atendimentos. (Entrevistada 09)

[...] ao lidarmos cotidianamente com diferentes problemáticas que envolvem cada política, a pesquisa permite subsídios para nossa prática. (Entrevistada 13)

É a partir das ações dia-a-dia que o Serviço Social se desenvolve e se atualiza, pesquisando e buscando um novo jeito de fazer, agir. (Entrevistada 15)

Na pesquisa, se investiga a situação que o profissional vai atuar ou abordar, trazendo subsídios para sua prática. (Entrevistada 19) 
Diante destas afirmações, é possível reiterar a importância dada à pesquisa pelos sujeitos do estudo. Para o assistente social, a pesquisa de situações concretas constitui um importante instrumento/ferramenta de trabalho, pois é o caminho necessário para a compreensão dos fenômenos sociais particulares com os quais lida no seu cotidiano, o que alimentam a elaboração de propostas fincadas na realidade e capazes de acionar possibilidades de mudança. O Serviço Social, como profissão sócio histórica, tem, em sua natureza, a pesquisa como meio de construção de um conhecimento comprometido com as demandas específicas da profissão e com as possibilidades de seu enfrentamento. Um dos campos empíricos estimuladores da atitude investigativa é, sem dúvida nenhuma, a prática profissional.

Muito embora os sujeitos pesquisados tenham sido unânimes em afirmar a existência da relação serviço social x pesquisa, e a grande maioria (85\%) considere que a pesquisa faz parte do seu cotidiano profissional, observamos que os mesmos não têm, efetivamente, realizado pesquisas. Há um esforço, por parte de alguns, em levantar dados sobre a realidade, em sistematizar dados do cotidiano profissional, em coletar informações, em elaborar diagnósticos sobre a realidade na qual estão inseridas, entretanto, esses dados não são tratados de alguma forma, conforme podemos observar nas falas abaixo:

A pesquisa que me refiro não tem um objetivo de divulgação científica, mas no espaço institucional tem contribuído para uma melhor compreensão do público com o qual trabalhamos. (Entrevistada 13)

A mensuração de vários segmentos como: opiniões; idade; sexo; classificação socioeconômica, bairro onde mora. (Entrevistada 16)

O cotidiano não permite uma pesquisa elaborada. (Entrevistada 20)

Dos sujeitos da amostra, $85 \%$ consideram que a pesquisa faz parte de seu cotidiano profissional e revelam três situações enfrentadas que possibilitam a prática da pesquisa: entendimento da realidade dos usuários para uma intervenção qualificada; sistematização e avaliação das atividades desenvolvidas; e como forma de atualização de informações sobre a área de atuação.

A primeira situação explicitada demonstra a necessidade da realização de pesquisas com foco nos elementos da própria realidade. Tal situação reforça o que já foi colocado, anteriormente, quando discutimos a relação entre o serviço social e a pesquisa. 
Esta afirmativa pode ser considerada, pois no espaço institucional em que atuo se faz necessário pesquisar diversos elementos da realidade dos usuários para poder intervir. (Entrevistada 13)

A pesquisa é indicada como um instrumento capaz de facilitar a sistematização da prática, por meio de avaliações e relatórios das ações desempenhadas pelos profissionais.

Sistematizando/revendo e avaliando nossas ações cotidianas através da construção de documentos elaborados a partir do trabalho realizado (relatórios quanti-qualitativos). (Entrevistada 02)

Por fim, a situação é reveladora da pesquisa como possibilidade de atualização de informações sobre a área de atuação do profissional do Serviço Social. Dessa forma, percebe-se que os sujeitos não se resumem à realização de pesquisas de caráter unicamente qualitativo, mas reconhecem o uso de abordagens quantitativas (estatísticas).

Atualizando dados, estatísticas, informações sobre área de atuação. (Entrevistada 12)

De acordo com as Diretrizes Curriculares da ABEPSS de 1996, fica clara a indissociabilidade entre a intervenção e a investigação, ou seja, a pesquisa funciona como um instrumento de grande relevância no processo de conhecimento da realidade concreta.

Esta relação é, de fato, reiterada o tempo todo por estudiosos do Serviço Social, entre eles, Pereira (2005), para quem a pesquisa, longe de ser um luxo intelectual, é uma necessidade inerente à profissão e é condição essencial para a ruptura com atitudes e práticas voluntaristas, tópicas e impensadas. Assim, a pesquisa não pode ser dispensada, sob pena de esvaziar o Serviço Social de pertinência científica e, portanto, de status de profissão de nível superior que se apoia em embasamento teórico nutrido por contínuas e sistemáticas investigações da realidade.

Para a autora, a pesquisa é parte integral e intrínseca do exercício da profissão, pois é na unidade entre teoria/prática/investigação/intervenção que o Serviço Social poderá encontrar a via alternativa, de sentido dialético, que tornará o profissional mais crítico e enriquecedor.

Quando questionados se consideram o assistente social um pesquisador, $95 \%$ das entrevistadas responderam que sim e apenas $5 \%$, que não. 0 dado acima evidencia, no seio da categoria, um novo perfil profissional, que percebe que a investigação não é uma 
atividade antagônica à intervenção, conforme assegura Pereira (2005). Se esse antagonismo ocorre, é devido a deformações profissionais que precisam ser urgentemente superadas, pois, sem investigação, a intervenção torna-se cega, e sem intervenção, a investigação torna-se inútil.

Para lamamoto (2003), um dos maiores desafios que os assistentes sociais vivem, no tempo presente, é desenvolver sua capacidade de decifrar a realidade, ou seja, de assumirse como profissional que pensa, analisa e pesquisa. Para efetivar esse perfil profissional, é preciso romper com as práticas meramente burocráticas e exclusivamente interventivas, marcantes na trajetória da profissão.

No que se refere à realização de pesquisas no âmbito profissional, $65 \%$ dos sujeitos afirmaram que as desenvolvem, enquanto 35\% responderam que não desenvolvem pesquisas no seu cotidiano profissional. Destacamos as seguintes falas:

[...] no espaço institucional em que atuo se faz necessário pesquisar diversos elementos da realidade dos usuários para poder intervir. (Entrevistado 13)

Não há como você visualizar o Serviço Social, mais especificamente, a atuação do assistente social sem fazer o uso da pesquisa, como um dos pontos de partida para uma análise daquilo que se apresenta como concreto. (Entrevistada 14)

Consideramos, neste estudo, que, no âmbito do Serviço Social, seja na área acadêmica ou na área de intervenção profissional, é imprescindível a utilização da pesquisa como instrumento científico para a sistematização do conhecimento dos fatos e dos fenômenos presentes no cotidiano profissional, para que se possa imprimir a marca da competência ao exercício profissional, conforme ressaltam Morais; Juncá; Santos (2010).

Quando indagadas sobre as dificuldades para a utilização da pesquisa no cotidiano profissional, o fator tempo aparece com muito destaque nas falas das pesquisadas, conforme se verifica abaixo:

O tempo limitado. (Entrevistada 02).

A necessidade de termos que dividir nossa carga horária entre 02 vínculos o que vem a diminuir nossa carga horária e automaticamente o tempo para desenvolvermos e analisarmos caso a caso nossas atividades perante os usuários, profissionais e familiares, isso inviabiliza a pesquisa. (Entrevistada 06)

A falta de tempo. (Entrevistada 11). 
O tempo é curto para atender a todas as demandas diárias no trabalho. Pelo fato de ter apenas eu como profissional e muitas atividades paralelas para organizar [...] (Entrevistada 12).

A impossibilidade de atuar em um único espaço institucional, já que por se tratar de escola tenho que me deslocar a 4 unidades. (Entrevistada 13)

A aplicabilidade, devido o número excessivo de atribuições, a pesquisa só é possível com o auxílio de acadêmicos e/ou estagiários. (Entrevistada 16).

De fato, a cotidianidade do processo de trabalho, de forma geral, apresenta uma multiplicidade de atividades que, ao se tornarem rotineiras e "programáveis", correm o risco de ofuscar o exercício do pensar sobre o que é realizado e sobre a própria realidade circundante. As mudanças no mundo do trabalho repercutem diretamente no fator tempo (LEWGOY, 2009).

A grande maioria dos profissionais de Serviço Social encontra-se inserida em contextos de trabalho precarizados, o que os obriga a ter mais de um vínculo empregatício, onde tudo depende de prazos, horários, datas, e, desse modo, não há, de fato, condições objetivas e materiais para o exercício da pesquisa. Nesse processo, a profissão sofre determinações estruturais que, contraditoriamente, tanto a desafiam, como, por vezes, lhe criam barreiras, impedindo que, na singularidade da prática profissional, muitos percebam a vinculação orgânica entre intervenção/investigação.

As limitações decorrentes do processo de formação também foram citadas como elemento dificultador da prática da pesquisa:

Primeiramente, limitações na formação e a incompreensão acerca da importância da pesquisa para a atuação profissional. (Entrevistada 04).

Reiteramos a importância do processo de formação na construção de um profissional pesquisador. Setúbal (2005) assevera que não podemos considerar a pesquisa apenas como resultante da formação em nível de pós-graduação, pois estaríamos desconsiderando a necessária sistematização dialética para a intervenção profissional. A pesquisa é indispensável ao assistente social em toda ação, seja na produção de uma tese na universidade ou em uma análise socioeconômica na instituição social, no seu cotidiano profissional.

Para Bourguignon (2008), a pesquisa envolve um processo de investimentos em formação profissional. A graduação é vista pela autora como espaço essencial para o 
desenvolvimento de uma atitude investigativa, com destaque para o momento de construção do Trabalho de Conclusão de Curso e do próprio estágio.

Cabe destacar que, no âmbito do Serviço Social, a pesquisa passa a ocupar um lugar de destaque a partir da incorporação do que estabelecem as Diretrizes Curriculares de 1996, no que se refere à relação indissociável entre a prática investigativa e a interventiva. Apesar dos assistentes sociais, historicamente, serem identificados como interventores por excelência, as atuais Diretrizes Curriculares, que orientam a formação profissional, entendem que, sem a investigação, o profissional não será capaz de desenvolver leituras competentes da realidade, que possibilitem a compreensão das expressões da questão social em sua totalidade.

Assim, o fortalecimento da pesquisa, na formação continuada de assistentes sociais, torna-se uma exigência e um desafio ainda mais urgente, diante da lógica de mercado que tem levado a uma flexibilização dos currículos e ao aligeiramento da formação profissional, com a expansão dos cursos à distância, o que tem gerado sérios desdobramentos, ou seja, o reforço da perspectiva utilitária e pragmática da prática profissional no enfrentamento da questão social.

Bourguignon (2008) ressalta que nem todos os profissionais conseguem manter viva a atitude investigativa e trabalhar a pesquisa em seu espaço institucional, visto que as exigências do mercado de trabalho ou as próprias exigências institucionais impedem uma prática vinculada à pesquisa. Tal fato é bem destacado nas falas das pesquisadas:

Não há oportunidade. (Entrevistada 08).

A importância (da pesquisa) é ímpar, porém, a prática não é fácil. (Entrevistada 14).

O cotidiano não permite uma pesquisa elaborada. (Entrevistada 20).

É fato que a pesquisa não se efetiva como deveria em todas as unidades de ensino e nos espaços sócio-ocupacionais. Estamos convictos de que há, ainda, muito a se avançar na prática investigativa no Serviço Social.

A formação de pesquisadores críticos e competentes desafia toda a lógica utilitarista, produtivista e mercadológica posta à educação superior no atual contexto. Os entraves e limites a esse processo, nas universidades, são inúmeros e complexos. 
De fato, podemos considerar que houve, no âmbito do Serviço Social, avanços significativos no que se refere à pesquisa, mas existem ainda muitas barreiras. Assim, é necessário um incentivo, por parte das universidades e instituições, para o desenvolvimento de um trabalho articulado, que tenha como horizonte uma atuação eficaz e competente, nos diferentes espaços de trabalho onde o assistente social está inserido.

\section{Considerações Finais}

O tempo presente é um tempo se encontra imerso em crises de natureza diversa: crise ecológica, crise de valores, crise do sistema educacional. No entanto, a crise do capital é a mãe de todas as crises. No dizer de Mészáros (2001), a crise que experimentamos hoje é uma crise estrutural do capital que vai se tornar, a certa altura, muito mais profunda, no sentido de invadir não apenas o mundo das finanças globais, mas também todos os domínios da vida social, econômica e cultural.

Em meio a essa conjuntura/estrutura de crise, situamos a necessidade de realização de investigações que possibilitem o "desvelamento" da realidade social, ou seja, é urgente a realização de pesquisas e estudos acerca do agravamento das expressões da questão social - objeto de estudo e de intervenção dos assistentes sociais. Não há dúvida que essa crise tem ampla e profunda repercussão no âmbito das políticas sociais, com suas conhecidas tendências de focalização, descentralização, desfinanciamento e regressão, contexto no qual se situa o fazer profissional do assistente social, que deve entender e atribuir visibilidade às derivações desses processos nos diferentes momentos e segmentos da vida social (IAMAMOTO, 2007).

Vale lembrar que o lugar privilegiado para o desenvolvimento de investigações é o espaço acadêmico, apesar de não ser o único. Nos dias atuais, convivemos, no âmbito acadêmico, com uma lógica mercadológica e utilitarista que atinge também a prática investigativa. De certa forma, o que ocorre é a incorporação do ensino superior à dinâmica do capitalismo, o que produz um tipo de capitalismo universitário, ou seja, o direcionamento da produção do conhecimento científico à funcionalidade do mercado (LARA, 2007).

A prática de pesquisa ainda está muito ligada aos cursos de pós-graduação, embora, nos últimos anos, aos poucos, esta tenha ocupado, também, o espaço dos cursos de 
graduação; isso se deve à criação de grupos e núcleos de pesquisa relacionados aos programas e às instituições de fomento.

Nesse sentido, não podemos deixar de considerar que a realização de pesquisas não ocorre de forma linear em todas as áreas do conhecimento, pelo contrário, é sabido que os investimentos em pesquisas nas áreas tecnológicas superam, em muito, os destinados às áreas das ciências humanas e sociais.

Associado a este fator, acreditamos que a situação chega a ser bem mais grave no que se refere à pesquisa em instituições privadas e à distância. Vale ressaltar que, após a Lei de Diretrizes e Bases da Educação de 1996, se efetivou uma abertura considerável à criação de cursos de graduação em instituições de ensino privadas e na modalidade à distância, inclusive, de cursos de Serviço Social.

Esse fator revela a subjunção da formação ao mercado, ou seja, a educação transforma-se, a cada dia, em uma mercadoria de alto valor que vem sendo comprada por filhos de famílias da classe trabalhadora.

Conforme pontua lamamoto (2003), somente alimentado por uma atitude investigativa, o exercício profissional cotidiano, em meio a todas as limitações que the são postas, tem ampliadas as possibilidades de vislumbrar novas alternativas de trabalho nesse momento de profundas alterações na vida em sociedade. A pesquisa é o caminho essencial para o desvelamento da realidade e para a construção de ações compatíveis com as necessidades dos usuários.

Nesse sentido, destacamos as palavras da autora (IAMAMOTO, 2008), para quem a investigação compromissada em libertar a verdade de seu confinamento ideológico é, certamente, um espaço de resistência e de luta. Uma utopia?

\section{Referências}

BOURGUIGNON, J. A. A particularidade histórica da pesquisa no serviço social. Revista Katálisys, Florianópolis, v. 10, p. 46-54, 2007.

BOURGUIGNON, J. A. A particularidade histórica da pesquisa no serviço social. São Paulo: Veras, 2008.

CARVALHO, D. B. B.; SILVA, M. O. S. (Org.). Serviço social, pós-graduação e produção do conhecimento no Brasil. São Paulo: Cortez, 2005. 
CONSELHO FEDERAL DE SERVIÇO SOCIAL. Assistentes sociais no Brasil: elementos para o estudo do perfil profissional. Brasília: CFESS, 2005.

FALEIROS, V. P. Reconceituação do serviço social no Brasil: uma questão em movimento. Revista Serviço Social e Sociedade, São Paulo, n. 84, 2005.

IAMAMOTO, M. V.; CARVALHO, R. Relações sociais e serviço social no Brasil: esboço de uma interpretação histórico. São Paulo: Cortez, 1985.

IAMAMOTO, M. V. O serviço social na contemporaneidade: trabalho e formação profissional. São Paulo: Cortez, 2003.

. Serviço social em tempo de capital fetiche: capital financeiro, trabalho e questão social. São Paulo: Cortez, 2008.

LARA, R. Pesquisa e serviço social: da concepção burguesa de ciências sociais à perspectiva ontológica. Revista Katálisys, Florianópolis, v. 10, p. 73-82, 2007.

LEWGOY, A. M. B. Estágio, ética e pesquisa: desafios para a formação profissional. Temporalis: Revista da Associação Brasileira de Ensino e Pesquisa em Serviço Social, Brasília, ano 9, n. 17, 2009.

MÉSZÁROS, I. A crise estrutural do capital. São Paulo: Boitempo, 2001.

MORAES, C. A. S.; JUNCÁ, D. M.; SANTOS, K. S. Para quê, para quem, como? Alguns desafios do cotidiano da pesquisa em Serviço Social. In: ENCONTRO NACIONAL DE PESQUISADORES EM SERVIÇO SOCIAL, 12., 2010, Rio de Janeiro. Anais... Rio de Janeiro, 2010.

NASCIMENTO, D. C. A pesquisa na prática cotidiana dos supervisores de estágio curricular do curso de Serviço Social da UEPB. Campina Grande, 2012.

NETTO, J. P. Ditadura e serviço social: uma análise do Serviço Social no Brasil pós-64. São Paulo: Cortez, 2007.

O movimento de reconceituação: 40 anos depois. Revista Serviço Social e Sociedade, São Paulo, n. 84, 2005.

. Transformações societárias e serviço social: notas para uma análise prospectiva da profissão no Brasil. Revista Serviço Social e Sociedade, São Paulo, n.50, 1996.

PEREIRA, P. A. P. A utilidade da pesquisa para o Serviço Social. Serviço Social \& Saúde, Campinas, v. 4 n. 4 p. 1-156, maio 2005.

RICHARDSON, R. J. Pesquisa social: métodos e técnicas. São Paulo: Atlas, 2007.

RODRIGUES, N. J. G. A.; FÉRRIZ, A. F. P.; NASCIMENTO, D. C. N. Gênero e serviço social: a prevalência da mulher nas cinco décadas de existência do curso de serviço social da 
Universidade Estadual da Paraíba. In: SEMINÁRIO NACIONAL GÊNEROS E PRÁTICAS SOCIAIS, 3., 2011, João Pessoa. Anais... João Pessoa, 2011.

SILVA, M. O. S. O serviço social e o popular: resgate teórico-metodológico do projeto profissional de ruptura. São Paulo: Cortez, 1995.

SETUBAL, A. A. Pesquisa em serviço social: utopia e realidade. São Paulo: Cortez, 2005. Desafios à pesquisa no serviço social: da formação acadêmica à prática profissional. Revista Katálisys, Florianópolis, v. 10, p. 64-72, 2007.

SPOSATI, A. Pesquisa e produção de conhecimento no campo do serviço social. Revista Katálisys, Florianópolis, v. 10, p. 15-25, 2007.

YAZBEK, M. C.; SILVA, M. O. da S. e; Das origens à atualidade da profissão: a construção da Pós-graduação em Serviço Social no Brasil. In: CARVALHO, D.B.B.de; SILVA, M.O. da S. e. (ORGs). Serviço Social, pós-graduação e produção do conhecimento no Brasil. São Paulo: Cortez, 2005. 